\title{
MAAS - MOBILITY-AS-A-SERVICE - IN THE ROAD FREIGHT TRANSPORT
}

\begin{abstract}
Undeniably, the fourth industrial revolution, which led to the formation of Industry 4.0, also significantly affects the sector of modern road freight transport. As a result, real transformation takes place in this sector, leading to the formation of Mobility 4.0 and Transport 4.0, and - closely related - Transport System 4.0. One of such new phenomena and trends in this area is Mobility as a Service (MaaS). The key principle - the heart of MaaS is to provide everyone who is the user member of that integrated system, with mobility, offered as a single, comprehensive and integrated service. That creates the ability to carry out any transport, while maintaining flexibility to change course - if necessary - even while moving.

In the case of freight transport in the situation of implementing Mobility as a Service, the contracting - participating party will get a much greater than presently personalized option - an optimized match in the selection of its various needs and requirements of the transport service available to it. The four underlying factors considered here will be the following variables: individualization, flexibility, cost and time.

The article is dedicated to the implementation of the idea - MaaS concept in freight transport - and the benefits resulting from that implementation for all parties included in the process described above.
\end{abstract}

Keywords: transport, MaaS (Mobility as a Service)

JEL: R40, R42

\section{Introduction}

Undeniably, the fourth industrial revolution, which led to the emergence of Industry 4.0, also has a significant impact on the modern road freight transport 
sector. As a result, the sector is undergoing a direct transformation, leading to the emergence and formation of Mobility 4.0 and - closely related to it - Transport 4.0 and Transport System 4.0. One of these new phenomena and trends in this area is Mobility as a Service (MaaS).

At the same time, although MaaS is a new phenomenon, there is already quite a rich literature on it. However, most of the available articles describe this MaaS phenomenon in the sphere of passenger transport. Meanwhile, in this article the author presented it in relation to the sphere of freight transport.

In this case the main objectives of the article are as follows:

- defining the idea - the MaaS concept in the field of freight transport;

- ways of MaaS implementing in the field of freight transport;

- the benefits, costs and challenges associated with the introduction of MaaS in the freight field;

- the emergence - the creation of new business models in the MaaS environment, in the sphere of freight transport.

The main part of the article is based on the analysis of the latest studies on this subject. Some of these studies come from research centers, some from well-known analytical and consulting companies. However, on this basis the author presented his own model of functioning of MaaS in the freight transport sector, because so far this model was used mainly in the passenger transport segment. In this context an important contribution of the author is defining what the MaaS concept - model means in the road freight segment and the indication of main benefits associated with the implementation of the MaaS concept in that part of the business.

\section{Defining Mobility as a Service}

The key principle - the heart of Mobility as a Service (MaaS) ${ }^{1}$ - is to ensure that every user involved in that system, by offering this mobility as a single, comprehensive and integrated service, is able to cover every journey, with the flexibility to change course - if necessary - even on the move. This means a key shift from a block to a much more flexible and targeted way of delivering mobility within dynamic systems. In this model, in freight transport, owners of means of transport of a given type that are not fully utilised in a given relation and time may make them available for a certain period of time, to a certain extent, under certain conditions and in certain relations to other, additional principals, depending on the needs of those principals in the sphere of the service of transfer (Benjaafar et al., 2018).

Until now, the ability to manage such an extremely complex system effectively has simply been too difficult to ensure the required level of sensitivity, reliability

\footnotetext{
That part is based on: Journeys of the Future. Introducing Mobility as a Service. Available from http:/ www.atkinsglobal.com/ /media/Files/A/Atkins-Corporate/uk-and-europe/uk-thought-leadership/ reports/Journeys $\% 20$ of $\% 20^{\text {th }}$ e $\% 20$ future_300315.pdf; https://www.cubic.com/Portals/0/16-CTS-W HITEPAPER-MaaS-v1-FINAL-lores-single\%20pages_1.pdf; Skills Deficit. The Consequences \& opportunities for UK infrastructure. Available from http://www.atkinsglobal.com/ /media/ Files/A/Atkins-Corporate/uk-and-europe/uk-thought-leadership/reports/The\%20Skills\%20Deficit\%20 Report\%20for\%20Water.pdf [Accessed 18 March 2019].
} 
and availability of the necessary amount of data at a specific time. This was due to the lack of the necessary data transmission channels to guarantee contractors customers - suppliers, senders, receivers, operators - the necessary precise information in real time, to help them decide, even when the vehicle is on the move.

In that case the current system of solutions existing in freight transport can be characterized by the following general terms:

- limited flexibility - usually the return journey should be secured in advance, and any search for it should take place at the latest at the time of the original unloading or shortly afterwards. Realistically, however, there are still limited possibilities to obtain cargo for the underutilized 'en route capacity', which affects the utilization rate of the vehicles (truck - trailer - semi-trailer) and thus limits the competitiveness of carriers;

- poor adaptability - the adaptation of transport services to respond to changes on the demand side. Operators and customers are struggling to adapt to changed patterns and structures, as sometimes there is still some inertia on the carriers' side;

- very difficult coping with network disturbances. In times of increasing disruption and non-linearity, the easiest thing to do is simply wait and suffer because there is no system in place to help customers deal with network disruptions quickly and efficiently;

- the fact, that it is extremely difficult in real terms to encourage principals to place orders in a balanced and sustainable manner. This means that incoming orders are very irregular, making it difficult for hauliers to work more rationally and sustainably through a more stable use of their vehicles - a more stable use of their load capacity and space over a long period of time. In general, hauliers experience a high fluctuation of incoming orders - i.e. periods when they are clearly getting them more or less. This occurs in a situation where equipment is used extremely intensively in some periods, and only to a certain extent in others. These areas therefore create new opportunities for the MaaS approach. By providing the customer with an integrated service, each specific task of moving a given volume from a specific point to a specific point can be done more flexibly. This is achieved by dynamically and flexibly matching the locations of loading and unloading points, the type of cargo and other specific requirements of the customer - the principal - to the available and continuously updated capacity and maximum volume of the network under consideration, creating a complete and complementary system, integrated and dynamically evaluating according to the requirements. However, this may require the customer to adapt their individual time and cost requirements to what the network may offer at any given moment. Shorter slots can mean higher costs. At the same time, however, the network ensures the availability of alternatives when problems arise and grow. The role of the network and its managers is to reduce the likelihood of any turbulence and, if it occurs, to eliminate any negative cost and time consequences as far as possible;

- relatively low capacity utilisation in real terms. In passenger transport, own cars are used daily for an average of only 1.5 hours, while jointly operated vehicles can be used daily for up to 8 hours. In such a system, for example, common 
taxis and minibuses can replace private passenger cars and typical city buses. As a result, in line with the Lisbon strategy, the aim is to achieve significant (dramatic) resource savings and to reduce external costs through the flexible use of passenger cars for individual mobility. In freight transport, on the other hand, there are still relatively high rates of empty or under exploited mileage, unnecessary returns and commuting, which is inextricably linked to the suboptimal use of payload and/or payload volume. Thus, only about $50 \%$ of the total capacity is currently realistically utilised by the physical movement of loads. However, in the case of long-distance operations, the average capacity utilisation rate is slightly higher-actually about $60 \%$. As a result, as much as $40 \%$ of unused capacity creates significant opportunities to seek optimization solutions. This $40 \%$ represents a reduction in productivity and, as a result, significantly lowers revenues at a given cost, as recorded by users. However, sometimes a small increase in costs could be associated with a better utilisation rate of vehicles with noticeably higher revenues.

However, advanced information and communication technologies and their strong penetration of our daily lives have created new opportunities for redesigning - the transformation of transport service delivery and real-time management of transport networks. This means that mobility opportunities can be delivered in a much more personalised - individualised way for each user and can reflect their specific needs and preferences. These mobility opportunities are also, importantly, available for on-demand - the starting point is not defined in the original timetable and on the map, and the order for a given journey that the customer intends to transfer, regardless of time and place, with the MaaS approach means that it can be realized for him in exactly the way he requires in terms of the specific cargo, time, places (loading, unloading) and other specific - individualized conditions that he requires.

In this model of mobility distribution, where the different transport needs of users are met through a single interface, provided by a single supplier, there is therefore a combination of different modes of transport from a single branch and even means of transport from different branches. As a result, the customer is offered a tailor-made package, sold in a manner similar to that of the world-famous telecommunication services. At the same time, issues related to the way of providing the interface, billing the service or selection of means of transport present in the available packages remain important here. In addition, not only the aggregation of modes of transport appears to be crucial here, but also the accessibility of the service and the way in which users gain access to $i^{2}$.

Peraphan Jittrapirom, Valeria Caiati, Anna-Maria Feneri, Shima Ebrahimigharehbaghi, María J. Alonso-González and Jishnu Narayan (Jittrapirom et al., 2017), in their collective work on defining Mobility-as-a-Service, point out that encouraging the use of transport services, including connecting by combined multimodal solutions, allows users to choose and facilitate their use. In this context, they have highlighted nine characteristics of this group of solutions, used in most

2 MaaS open ecosystem. Available from https://maas.global/maas-as-a-concept/; Mobility as a Service PL (2018), Pierwszy przekrojowy raport z polskiego rynku MaaS, Raport Straal, Warszawa. Available from https://res.cloudinary.com/dikm0e8eo/image/upload/v1541003517/Mobility-as-a-Service-PL.pdf, p. 12. 
of the definitions. By transferring (adopting) these features to only freight transport sphere, they will express the following:

1. Integration of all modes of transport - means of transport from all modes of transport - into one uniform and integrated system. If, for specific and objective reasons, it has become impossible to integrate means of transport from several modes in a co-modal way, the issue is to optimize in organizational, cost, time and resource systems the means of transport from one, in a particular case - in a given situation the most appropriate to perform a given movement in a given relation, under given conditions, with given restrictions.

2. The choice - selection of an available tariff option(s). The MaaS platform offers users several types of tariffs for accessing their mobility services - such as monthly package fees or pay-as-you-use fees, i.e. pay for what you use. The package offers modules of different types - modes of transport and includes a number of kilometers/carriage work carried out/points serviced, which may be used in return for a monthly or fixed payment in other billing periods, for example, weekly billing periods. Fees may therefore be user-dependent and will be charged to users in accordance with their efficient use of the service.

3. One platform. MaaS is based on a digital platform - a mobile application or website, which can be used by end users to receive the access to all necessary (required) services related to transport, such as route planning, reservation, access sales, payments and real-time information. Users can also receive - be given access to other useful services such as synchronizing with their own calendar of activities, reporting on their operations, invoicing and feedback.

4. Many parties involved in the MaaS ecosystem are built on the basis of interactions between different stakeholder groups - parties involved in the system by means of digital platform technology. As a result, it includes: payers, transport service providers - carriers and platform owners. Other actors can also work together to make the service work and improve its efficiency. These are, for example, local authorities, billing agents, telecommunication operators, consultancy companies and vehicle suppliers, who ensure that these vehicles remain fully mobile and thus fully operational.

5. Used technologies. Various technologies are combined to enable the smooth operation of MaaS: devices such as laptops and smartphones; a reliable mobile internet network (WiFi, 3G, 4G, LTE); GPS; an electronic payment system; a database management system and an integrated technological infrastructure such as IoT.

6. Orientation - focusing on demand - because MaaS is a user-oriented paradigm. It strives to offer a transport solution that turns out to be the best from the point of view of the customer under given conditions and with given limitations. This choice can be made by means of a multimodal transport planning function and by taking into account the momentary demand for services.

7. Registration required. The end-user must join the platform in order to gain access to the services it offers. An account may be valid for a particular company or, in some cases, for a group of companies or a broker such as a logistics operator. Subscription not only facilitates the use of services, but also enables their 
greater personalisation - optimised flexible adaptation to the needs of a specific customer.

8. Personalization. It ensures that the requirements and expectations of end users are met more effectively and efficiently, taking into account the uniqueness of each customer. The system provides the end-users with specific recommendations, with customized solutions - tailored to their needs based on their profile/expressed personal preferences and past orders. In addition, users can connect their existing contacts and other order handling platforms previously used - operated by them (for some time).

9. Customization. It allows end users to modify the service options offered to them according to their preferences. This can increase the attractiveness, satisfaction and loyalty to MaaS among customers and their customers. They can either quite freely compose specific transport tasks with their logistics chain (sourcing and/or distribution) or build their own mobility support package with different options available and mobile use of certain modes - modes of transport and means of transport from a given mode - in order to maximise their benefits resulting from a given transport operation.

In addition, to make the offer more attractive, there is the option of flexible and individualised inclusion of additional services, such as cargo insurance, certain forwarding formalities or other items/activities, according to specific needs and requirements.

Thus, since the $\mathrm{MaaS}^{3}$ model combines all modes of transport, aggregating by integrating the options of different transport providers into a single mobile service, it eliminates the problems of planning and one-off payments because each mode of transport is combined into one intuitive mobile application. This seamless combination of transport options from different suppliers - as an integrated system -supports everything from transport planning to payment. With this system, MaaS manages the transport needs of the customer in the most cost, time, organisational, resource and environmental optimized way, under the given conditions and with the given constraints. That is why it concerns the proper planning of the route, parking, the necessary reloading and even the maintenance of the vehicles in use in the real time - as a part of up-time maintenance support module-so-called preventive maintenance service. As a result, MaaS has the opportunity to revolutionise mobility in a genuine way, covering not only self-propelled vehicles, but also less congested transport routes. In that case - for the system user - the issue concerns not only the movement of the given load from point $A$ to point $B$, but also the entire organizational and executive side of the process. If transport services can therefore be digitally integrated to make them really convenient and easy to use, there will be a significant increase in productivity, while reducing costs and pollution.

The implementation of the MaaS-based approach, expressed by looking at the system as a compact whole, can result in the creation and presentation to the customer of a single, integrated, uniform and coherent network platform. The range of available transport options and the complexity it represents mean that the trend towards choice will become common and constant.

3 MaaS open ecosystem. Available from https://maas.global/maas-as-a-concept/ [Accessed 21 March 2019]. 
As a result, for the customer - MaaS customer-Mobility as a service presents itself as the integration of the transport system into a whole, through the combination of different types of mobility and all the related (dedicated to it) information into one coherent and logical system. Moreover, such integration is only one issue. Another key fact remains that the customer requires one interface - an entry to the entire network in order to understand easily and better the available options for each specific movement. Therefore, it is a critical task of MaaS to deliver - to propose a simple, integrated platform to be used by customers to place orders. Another important issue here is the method of payment for the order itself. A key part of this is the assumption that mobility as a service is an analogy to communication and software.

In particular, when considered in such a context, this type of mobility could develop a model similar to today's mobile phone use model, meaning that:

- different payment methods and options are adopted for all types of transport: daily, one-off, occasional, permanent;

- different types of services will serve in order to further optimize the different needs expressed by different users;

- additional options will be easily available to complement the basic transport contract, such as extended insurance, availability of other modes of transport, packaging, warehousing, full forwarding and logistics services, delivery options in different locations. This system is fully eclectic and can be further developed - it has an open architecture and is prepared for changes and challenges in the future connected with its development - so it is an open and evaluative system. Base contracts can already be used to encourage principals to improve flexibility in their operations. The demand side is to be made more flexible for the most efficient use of the supply side in time, organization and cost arrangements. For example, if delivery takes place during peak hours or periods, it will be more expensive. The price of transport services may also depend on driving conditions - increasing during storms, snow or strong winds, causing a significant increase in transport costs on the part of carriers, usually not yet compensated by the ordering parties. This is all the more so because in highly developed countries attention is paid to the problems of congestion, air pollution and noise emissions. So the aim here is to gradually implement the so-called zero-emission transport.

At the same time, due to its specific characteristics, including the infrastructure used and the characteristics of the means of transport and the way in which movements are carried out, including the flexibility in the field of time and route selection, road transport is the most susceptible to the implementation of MaaS in freight transport. This is due to its immanent characteristics, of which in this case - in the implementation of MaaS - the key ones remain:

- high availability;

- the greatest of all modes flexibility in the choice of the main route and possibly alternative routes;

- ease of access - the highest rate of accessibility;

- the possibility of carrying out door-to-door orders;

- high ease of loading and - if needed - reloading; 
- the rare operations that can be performed according to a specific timetable, while rail, air and sea transport to a large extent operate according to a fixed timetable. As a result, in these modes of transport the movements of goods are carried out in accordance with the specific time and location requirements. It is caused by the fact that in these modes it is limited or even impossible to perform operations very flexible - at free but given time and on a given route. Another main obstacle is connected with low availability on demand two crucial assets and services: means of transport and access to infrastructure.

\section{Introducing Mobility as a Service}

The key role of so called smart mobility is that it can play a key role in supporting a wide range of economic, social and environmental changes. This is due to the fact that smart mobility is a new way of thinking about how to connect people, places and loads in a single system covering all modes of transport. It is about how to use the combination of systems - thinking and perceptions, technologies and data within the transport network to inform those responsible for decision making and to allow for the necessary structural and conceptual changes. Smart mobility combines a strong focus on placing the principal at the center of the transport service offered, proposed together with the requirement to integrate all transport capacities into a coherent, holistic, networked and integrated system. Four issues are crucial in this context:

- Mobility as a Service - focusing on a customer-centered approach to mobility and how to deliver an efficient use of the integrated transport system;

- use of information - understanding how new technologies can help analyse data to generate new conclusions, insights and find new areas for further improvement in the fields of efficiency and use;

- order management - looking for ways to deliver cargo without time and cost losses what means reaching the maximum reduction of inter-loading - "empty time" and resource wastage;

- future roads - analyzing how autonomous vehicles and smart infrastructure will look and develop in the near future.

Moreover, in the traditional model, transport was able to provide a constant level of transport service delivery in order to secure the forecast demand and thus anticipate the processes taking place and to form a set of factors for anticipating demand in the future. Meanwhile, the opportunity offered by new technology lies in the possibility of creating a model, in which the situation would be reversed. In this new solution, transport supply would be tracked in real time by principals and further optimised by further dynamic matching of demand to available capacity - space and tonnage - represented in a given moment in a given area by the whole network. For example, the MaaS models will be able to capture changes in demand and redirect them entirely or partially to other partners, other times of the day, etc., in order to more flatten the temporary use of available vehicles on the one hand and the use of available infrastructure on the other. Alternatively, incentives may be introduced, such as dynamic pricing to convince - to encourage 
customers not to place transport orders during peak hours/peak periods and thus contribute to spreading their demand over a larger number of hours - different times of the day or other periods of the week, month or quarter.

\subsection{Benefits and costs resulting from the implementation of MaaS models - MaaS system}

When implementing Mobility as a Service, contracting parties will have a much greater opportunity than at present to personalize their different needs and requirements of the transport services available to them. The four underlying factors considered here will be the following variables: individualization, flexibility, cost and time. The following dependencies will be formed between them (Table 1).

Table 1. Shaping the relationship between the four factors considered in the MaaS model

\begin{tabular}{|c|c|c|c|c|c|}
\hline Features & $\begin{array}{l}\text { Delivery of cargo for } \\
\text { the time indicated }\end{array}$ & $\begin{array}{c}\text { Flexibility } \\
\text { in transport - } \\
\text { taking into account } \\
\text { the needs of other } \\
\text { contracting } \\
\text { authorities }\end{array}$ & $\begin{array}{l}\text { Possibility } \\
\text { of picking } \\
\text { up other } \\
\text { cargo }\end{array}$ & $\begin{array}{l}\text { Total } \\
\text { journey } \\
\text { time }\end{array}$ & $\begin{array}{c}\text { Total cost } \\
\text { of pro- } \\
\text { viding } \\
\text { the service } \\
\text { to the prin- } \\
\text { cipal } \\
\end{array}$ \\
\hline $\begin{array}{l}\text { Full } \\
\text { individu- } \\
\text { alization }\end{array}$ & Total & None & None & Short & High \\
\hline $\begin{array}{l}\text { Flexible } \\
\text { individu- } \\
\text { alization }\end{array}$ & Total & Restricted & Restricted & $\begin{array}{l}\text { Extended } \\
\text { in the case } \\
\text { of addi- } \\
\text { tional } \\
\text { loading } \\
\end{array}$ & Reduced \\
\hline $\begin{array}{l}\text { Flexible } \\
\text { individu- } \\
\text { alizing }\end{array}$ & $\begin{array}{l}\text { Possible - option } \\
\text { to adjust the loading } \\
\text { torque }\end{array}$ & Large & None & Long & Average \\
\hline $\begin{array}{l}\text { Full } \\
\text { flexibility }\end{array}$ & $\begin{array}{l}\text { No option - } \\
\text { the vehicle will arrive } \\
\text { at the indicated place } \\
\text { after the load according } \\
\text { to the time accepted } \\
\text { by the operator/carrier. } \\
\text { The ordering party } \\
\text { will be informed } \\
\text { about the specific time } \\
\text { of arrival of the vehicle } \\
\text { at the time of ordering } \\
\text { the service. Of course, } \\
\text { for objective reasons, } \\
\text { some delays are } \\
\text { possible. }\end{array}$ & Full & Full & Longest & Low \\
\hline
\end{tabular}

Source: (own elaboration) 
The separation of these variables and characteristics allows to propose four baseline approaches in the MaaS model prepared for freight transport:

- full individualization;

- flexible individualization;

- flexible individualizing;

- full flexibility.

These approaches represent the situation considered from the perspective of the haulier and basic - particular customer.

In the case of full individualization, the entire transport service is provided only on behalf of a particular customer, according to their guidelines for the selection of dates, places and, if applicable, the route. The journey will therefore take place at the exact time indicated by the customer. There will also not be additional loading during the trip, even if the vehicle has not yet fully utilized capacity in terms of space and/or payload volume. As a result, the journey time will be the shortest. However, such individualization will result in the highest price of such a service. Consequently, in this model, the system fully adapts to the requirements of the customer.

In the case of flexible individualization, the means of transport arrives for the time indicated by the original customer. However, in this model, if the customer does not make full use of the available loading space and/or payload available in a given vehicle, there is an option to take an additional load "on the route". As a result, the total journey time may be extended, but - from the point of view of the original customer - with a certain reduction in the costs of such a service. Consequently, there is a certain hybridization. The transport system adapts to the individual needs of the customer only in terms of the time of arrival - arrival at a specific place indicated by the customer, but then the customer submits to this system, having to agree to a possible extra - additional loading, from the customer's perspective, which prolongs the driving time but reduces its costs. Part of the costs of that journey will be covered by the party whose cargo has been added 'en route' to the considered means of transport.

In the case of flexible individualizing, the vehicle arrives at the customer only when it becomes available - i.e. from the point of view of the operator or carrier, it was closest to the place of loading after having previously unloaded or arrived from the base. The contracting authority therefore agrees to the arrival time indicated by the operator or carrier and has to adapt to it. In this model, therefore, it is the original contracting authority that adapts to the availability of the transport service with the required parameters, and not the carrier or operator that adapts the service - i.e. the availability of vehicles - to the contracting authority's requirements in this respect. The required vehicle arrives when it becomes available and not when the contracting authority wishes - so in this case the arrival time might not fully comply with the needs and requirements of goods' sender. Thus, in the area indicated, it is the purchaser who adapts his loading time to the system, not the system to him. As a result, it slightly reduces the expenditure allocated to this purpose. And this is the only such a fit in this third model. As in the first model - full individualization - in the case of not full utilizing load capacity and/or load space, it is not possible to load "on the road" - this means that only the originally - after 
the first loading - used loading/cargo space is utilized. As a result, it is not possible to reduce costs.

In the last - fourth case - the service buyer - ordering party fully complies with the system's algorithm. The vehicle arrives at the time indicated by the system, not by the buyer, and it is possible to take additional loads "on the route" if the load capacity and/or load volume still available in the vehicle allow for this. In this case, the time of a single transport is extended, but at the same time its costs decrease significantly - in this model they are the lowest possible costs for each of the ordering parties. In other words, for the longest transport time, the ordering party benefits from the lowest possible costs.

With strict time limits, the best model for the customer is the first model. But in that model, connected with the lack of flexibility - a fully individualized provision of this transport service, which translates into the shortest possible delivery timecustomer has to pay the highest fee. The lowest costs are borne by the ordering party in the fourth model - full flexibility. In such a case, it has to adhere completely to the "system", which means that the time of a given movement can become the longest.

One example of a real implementation of the MaaS concept in road freight transport is another source of revenue thanks to data-based new business models, such as capacity as a service or dynamic road planning and matching - also dynamic loads (dynamic matching of loads to dynamic road planning or dynamic planning of loads to a previously planned route, but which may be subject to some later changes). In the latter case, the issue concerns the so-called dynamic - active real-time cargo management programmes for increased transport efficiency. The issue relates to the real-time transmission within the integrated network: on the one hand, information about the moving vehicle with incomplete load capacity and/or loading space and the type of cargo it can take, and on the other hand, about the free loads located along the route of the vehicle and/or in its vicinity, with a maximum of several dozen-kilometer-long access roads to warehouses or distribution centers for additional loading allowed. The above is realized in several phases, by reducing not fully or even completely unused space, shortening the time necessary to perform each task - understood as moving each load in the shortest time - shortening the time of execution of each order, and limiting - efficient reduction of the environmental footprint - the negative impact on nature. Then, while driving, the vehicle receives information on where to take such an additional load. What's more, such an intelligent system guides the vehicle to this load at all times: it indicates the departure, in the warehouse or logistics center it immediately shows the number of the loading ramp and the way to it, and indicates the time slot for the necessary operations. In addition, in the indicated time slot, the cargo is already waiting at the loading ramp to be placed in the vehicle, and is not just being searched for or taken from its storage location. This minimizes time losses and reduces costs, among other things. The driver does not wait at the yard or under the ramp, does not look for a way to get there - he immediately goes to the loading area and is serviced there. In addition, if, for certain reasons, the vehicle originally indicated cannot accept the order, the system is "dynamic". So in real time it searchers for the next vehicle, at a given moment driving in a specific relation 
and being technically prepared to take the cargo of a specific type. The issue - which is an advantage here - concerns, of course, the ability to prepare such an "intelligent" algorithm, which optimally associates all the components considered in this model.

Thus, the biggest challenge for the industry today is to prepare such an "intelligent" algorithm that collects and analyzes as many variables - that are key to the model - as possible in real time. The issue of a dynamic search for cargo seems to be one of the most important factors, especially due to the lack of proper flow of goods in the transport system and on-time - in real time sharing of information between all stakeholders. As a result, approximately 30 to even $50 \%$ of the capacity of semi-trailers is not fully utilised and $25 \%$ of journeys are empty, which means that the capacity of semi-trailers is not utilized at all in this situation (Schulze-Isfort, 2018).

\section{Conclusions}

In general, thanks to MaaS, all the parties involved in that model always benefit from cooperation in joint consumption with other partners, as this allows them on the one hand to increase revenues and profit margins, and on the other to reduce costs. In this case, such joint consumption means that the benefits are maximised multilaterally. MaaS offers tailor-made mobility solutions for the users involved in the platforms in order to achieve a more sustainable transport system. This change of purpose is to take into account the social context in order to meet the needs of users and at the same time the environmental aspect, taking up the challenge of the clean and bio-neutral mobility in freight transport. The implementation and delivery of innovative services such as MaaS will therefore certainly help to increase accessibility and efficiency by moving from restricted to open, access-based transport. More specifically, it is expected that the wide range of alternative options available, including these from different modes, and non-standard mobility services will have social value, increasing the efficiency of mobility and the ability to share the transport system as a whole and its different modes. The latter feature plays an extremely important role when the orders concern the handling of less accessible areas or principals with a lower willingness to pay for a given service on given terms and conditions (Dotter, Szmigielski, Maes, 2016).

\section{References}

Benjaafar, S., Kong, G., Li, X. et al. (2018), Peer-to-Peer Product Sharing: Implications for Ownership, Usage and Social Welfare in the Sharing Economy. Available from https://pdfs.semanticscholar. org/f1e6/16e34ab128278ae9d8b5f2dfde562cff01e7.pdf.

Dotter, F., Szmigielski, R., Maes, N. (2016), Mobility-as-a-Service: A new transport model. CIVITAS. Available from http://civitas.eu/content/civitas-insight-18-mobility-service-ne w-transport-model.

https://www.cubic.com/Portals/0/16-CTS-WHITEPAPER-MaaS-v1-FINAL-lores-single\%20 pages_1.pdf. 
Jittrapirom, P., Caiati, V., Feneri, A.-M. et al. (2017). Mobility as a Service: A Critical Review of Definitions, Assessments of Schemes, and Key Challenges, Urban Planning, 2(2), pp. 13-25, doi: 10.17645/up.v2i2.931.

Journeys of the Future. Introducing Mobility as a Service. Available from http://www.atkinsglobal. $\mathrm{com} / \sim /$ media/Files/A/Atkins-Corporate/uk-and-europe/uk-thought-leadership/reports/ Journeys $\% 20$ of $\% 20^{\text {th }} \mathrm{e} \%$ 20future_300315.pdf.

MaaS open ecosystem, website https://maas.global/maas-as-a-concept/.

Mobility as a Service PL (2018), Pierwszy przekrojowy raport z polskiego rynku MaaS, Raport Straal, Warszawa. Available from https://res.cloudinary.com/dikm0e8eo/image/upload/ v1541003517/Mobility-as-a-Service-PL.pdf.

Schulze-Isfort, G. (2018) Going digital within global trends - vision of a trailer manufacturer, internal study, Krone.

Skills Deficit. The Consequences E opportunities for UK infrastructure. Available from http://www. atkinsglobal.com/ /media/Files/A/Atkins-Corporate/uk-and-europe/uk-thought-leadership/reports/The\%20Skills\%20Deficit\%20Report\%20for\%20Water.pdf.

\section{Corresponding author}

Jarosław Brach can be contacted at: jaroslaw.brach@ue.wroc.pl 